\title{
"Balance as a way of lifework": early career choices among Israeli senior teacher educators
}

\author{
Mary Gutman
}

\section{QUERY SHEET}

This page lists questions we have about your paper. The numbers displayed at left are hyperlinked to the location of the query in your paper.

The title and author names are listed on this sheet as they will be published, both on your paper and on the Table of Contents. Please review and ensure the information is correct and advise us if any changes need to be made. In addition, please review your paper as a whole for typographical and essential corrections.

Your PDF proof has been enabled so that you can comment on the proof directly using Adobe Acrobat. For further information on marking corrections using Acrobat, please visit http://journalauthors.tandf.co.uk/production/acrobat.asp;

https://authorservices.taylorandfrancis.com/how-to-correct-proofs-with-adobe/

The CrossRef database (www.crossref.org/) has been used to validate the references. Changes resulting from mismatches are tracked in red font.

\section{AUTHOR QUERIES}

Q1 Please note that the ORCID for Mary Gutman has been created from information provided through CATS. Please correct if this is inaccurate.

Q2 Please provide missing Department for the affiliations.

Q3 The funding information provided has been checked against the Open Funder Registry and we failed to find a match. Please confirm if the Funding section is accurate and also confirm the funder names.

Q4 The reference "Author, 2019a" is cited in the text but is not listed in the references list. Please either delete in-text citation or provide full reference details following journal style [Standard APA]

Q5 The reference "Author, 2018 " is cited in the text but is not listed in the references list. Please either delete in-text citation or provide full reference details following journal style [Standard APA]

Q6 The year for "Ariav et al., 2013" has been changed to 1993 to match the entry in the references list. Please provide revisions if this is incorrect.

Q7 The year for "Council of Higher Education (CHE), 2015" has been changed to 2016 to match the entry in the references list. Please provide revisions if this is incorrect.

Q8 The reference "Author, 2020" is cited in the text but is not listed in the references list. Please either delete in-text citation or provide full reference details following journal style [Standard APA] 
Q9 The reference "Author, 2019b" is cited in the text but is not listed in the references list. Please either delete in-text citation or provide full reference details following journal style [Standard APA]

Q10 The disclosure statement has been inserted. Please correct if this is inaccurate.

Q11 Please provide missing Publisher location for the "Creswell, 2013" references list entry.

Q12 Please provide missing volume number for the "Hulme et al., 2015" references list entry.

Q13 Please provide missing Publisher location for the "Marshall and Rossman, 2014" references list entry.

Q14 Please provide missing volume number for the "Maxwell and Miller, 2008" references list entry.

Q15 Please provide missing volume number for the "Schuck et al., 2017" references list entry. 


\title{
"Balance as a way of lifework": early career choices among Israeli senior teacher educators
}

\author{
Q1 Mary Gutman (iD) \\ Q2 Efrata College of Education, Jerusalem, Israel; The Mofet Institute, Tel Aviv, Israel
}

\begin{abstract}
This study seeks to explore Israeli senior teacher educators' retrospective interpretations of their early career experiences while addressing a special emphasis on cultural and contextual characteristics of the academic colleges of education (ACEs). In order to study in depth the attraction factors of career choices among teacher educators, who have outstanding academic skills and background in university teaching, 10 semi-structured interviews were conducted. The findings pointed to the 'balancing between different fields of work' as a major attraction in choosing both the profession and the academic home among teacher educators. Moreover, three balancing points of utmost importance in career choices are identified as significant: a balance between theory and practice toward educational change; a balance between self-worth and production-based worth; and a balance between social relevance and professional networks. The study concludes with a handful of recommendations for ACE administrators on the strategies of recruiting and retaining new teacher educators with impressive academic achievement.
\end{abstract}

\section{ARTICLE HISTORY}

Received 20 July 2019

Accepted 2 July 2020

\section{KEYWORDS}

Teacher educators; career choices; professional identity

\section{Introduction}

The career trajectories of faculty members in higher education institutions are characterized by various challenges for early-career faculty, including the need to integrate into the institution and adapt to a new academic culture, which is sometimes different from theirs. This trend also applies to faculty members in academic colleges of education (ACEs) who, in addition to meeting specific academic criteria, are also expected to demonstrate a rich background in education and previous teaching experience in schools. Recent research indicates that many grow up in the field and integrate into teacher education institutions after proving themselves as being excellent school teachers (White, 2014; Wood \& Borg, 2010). Their first period of work (known as an 'early career') is characterized by a searching for teaching, academic and research identities (Griffiths, Thompson, \& Hryniewicz, 2014).

The academic literature on career development of teachers and teacher educators reveals widespread preoccupations with research on early career stage, which is defined as a critical short-term period that usually lasts from three to five years starting from the day the employee is admitted into the new organization (Henry, Bastian, \& Fortner, 
2011). In terms of daily tasks, this stage is characterized by processes of socialization and recognition of the different components of the job (Goodwin et al., 2014). In social terms, this is a stage in which the employee builds a professional social network in the workplace, in order to gain legitimacy and support from the professional environment (Ewing \& Manuel, 2005). In emotional and micropolitical terms, the employee strives to recognize the organizational culture, power relations and the different textures of the internal hierarchy (Schuck, Aubusson, Buchanan, Varadharajan, \& Burke, 2017). As a result of the combination of these aspects, the employee develops an early career resilience which guides his or her future professional choices (Author, 2019a).

In the context of a teacher educator's professional path, the early career is described in many sources as a second career that experienced teachers aspire to, after many years of teaching in schools (Murray, Czerniawski, \& Barber, 2011; Murray \& Male, 2005; Trent, 2013; Williams, Ritter, \& Bullock, 2012; Wood \& Borg, 2010). However, the accepted reality in Israel is that there is a small wave of novice teacher educator who were integrated into ACEs, while having well-developed academic skills: they often hold a P.Hd and may have experience as research and teaching fellows at universities. Their choice of this professional course is not self-evident, given that there is a significant gap in the terms of employment between two types of institutions. College-based educators are required to teach 16 hours per week, which is twice as much as their university counterparts who teach only eight (Katz \& Coleman, 2001). The shortage of high academic orientation teacher educators has created difficulty in recruiting appropriate faculty members who fit the spirit of the academicization of ACE (the academic reform that began at the time).

Upon the lack of studies on the impact of these processes on the integration of highly qualified teacher educators into ACEs, the current research seeks to trace the experiences of this minority group, and to chart their professional choices retrospectively. This is in pursuit of a precedent thought among policymakers in teacher education institutions experiencing similar processes.

\section{Academization in teacher education}

International organizations have always argued for the importance of educating teachers and their capacity for career-long learning, with the understanding that these influence teaching performance and educational outcomes in practice (Hulme et al., 2015, p. 37). Researchers, such as Cochran-Smith (2003) support this statement, adding that the dependence on three aspects (improving the level of educational outcomes in schools, ACEs' ability to prepare new teachers for the field in both academic and pedagogical aspects, and lifelong learning ability of teacher educators) remains undisputed. A variety of recommendations have emerged in recent research into academic reforms in teacher education systems around the world, with the aim of highlighting the best integration of theories, field-based evidences and research practices (Cochran-Smith, Stringer Keefe, \& Carney, 2018). In this context, they mentioned reforms that led to, raising the academic level of teacher preparation, which contained moves such as setting requirements for $M$. A. degree as a prerequisite for entry into the school teaching, increasing the demands for conducting research among academic staff, and finally - the tendency of merging the higher educational sectors and institutions in order to balance, its quantity and quality. 
This reality of reform is clearly reflected in the Israeli ACEs. In order to improve their academic position, about 30 years ago, a reform called 'academization' of ACEs was conceived. Part of its expressions was the rebranding of colleges and their renaming, from a 'teacher training college', to an 'academic college of education' (ACE) and began certifying its graduates with a bachelor's degree (B.Ed) alongside a teaching certificate. On the practical level, in this period, the academic promotion tracks were opened for staff, and later, the ACEs began to receive approval for the advanced degree programs ( $M$. Ed and $M$. Tech). All of these have created a growing demand for the development of a research culture and the recruitment of teacher educators with clear research orientation and willingness to continue professional development processes (Fresko \& Nasser-Abu Alhija, 2015; Hofman \& Niederland, 2012). During this period, when many veteran teacher educators had not attained PhD degrees or experience in conducting academic research, the novices who had completed research tracks at leading universities around the world, and even gained experience in teaching at universities, were a valuable and precious resource for the colleges (Shagrir, 2015; Shamai \& Kfir, 2002). Taking a broad view of this group of academics, it is possible to identify patterns of coping with various dilemmas regarding their professional choices (Author, 2018; Margolin, 2011; Olsen \& Buchanan, 2017).

\section{Research context}

The need to promote the status of teachers in Israel requires ACEs to set high standards for the quality of teaching and research, and to develop academic abilities among graduate students and lecturers (Ariav, Kfir, \& Feigin, 1993; Hofman \& Niederland, 2012). These efforts, which were heralded as the academization policy of ACEs, are mainly intended to disengage ACEs from subordination to the Ministry of Education, which places great emphasis on exposure to practical pedagogic experience, and to transfer to the supervision and budgeting of the Council for Higher Education. The latter demands high academic standards and expects faculty members to develop an identity oriented to active research, as required by other institutions of higher education (Shagrir, 2015). To reinforce such identity and encourage research, new promotional ranks were opened in 2005 for senior faculty members employed by ACEs, including the rank of 'associate professor' (Council of Higher Education [CHE], 2016).

The academic staff members of ACEs, also known as 'teacher educators,' are identified as part of the higher education teaching community. However, their professional identity is controversial in the eyes of the academic world (Ellis, McNicholl, Blake, \& McNally, 2014; Griffiths et al., 2014; Kosnik et al., 2011; Trent, 2013; Williams et al., 2012; Wood \& Borg, 2010). On the one hand, teacher educators are expected to develop theoretical knowledge and international research as part of the requirements of the Council for Higher Education. On the other hand, the main demands of their work consist of teacher training in methods applicable to the various disciplines for practical work. When the policy of academization was first implemented in ACEs, a distinction was created between two cultures. The first is the university culture, which sanctifies academic outputs and deals with research as an end in itself, seeks a proven track record of influencing the academic world, and encourages interpersonal interactions for mutual benefit for research. Then, there is the second-tier academic culture (that of the ACEs), which is expressed in an emphasis on processes rather than on academic outcomes, the lack of any interpersonal competition, the perception of research as a tool for promoting pedagogy and education, 
Q8 and the development of personal relationships as an end in itself (Author, 2020; Yemini et al., 2015). This gap is more of a challenge for those seeking to shift their careers from one academic culture to another. In light of these facts, and considering the scarcity of studies of the early careers of teacher educators in this context, this study examines the attraction factors in early career choices among research-oriented teacher educators toward their integration in ACEs in the era of the beginning of the academic reform.

\section{Methodology}

\section{Sample and procedure}

The current study was based on criterion sampling method (Patton, 2002). The criteria for inclusion were: experience as teacher educator at ACE of 20 years at least, senior academic rank, and previous experience as staff member at research institute or university. Adherence to these criteria was intended to allow in-depth exploration of the professional choices of those who have been exposed to various academic cultures and who began their careers at ACEs alongside the initiation of academization reform. Moreover, focusing on senior academics as a research objects enables a broad retrospective view of past experiences of 'models and mentors' who had built a successful career in teaching and research, despite the local challenges of institutions (Douglas, 2013). Thus, the sample included 10 senior teacher educators (six male and four female) from six Israeli ACEs who hold the rank of 'associate professor', seniority of 25 to 35 years in ACE and previous background of teaching in universities.

A semi-structured interview, which was planned in advance and conducted by the author, was intended to encourage the interviewees to share their life stories. In line with this approach, the interviewee shares his or her life story with the interviewer, emphasizing concepts, beliefs, considerations, dilemmas and special experiences that are engraved in his or her memory from the period defined by the research question (Marshall \& Rossman, 2014). The interview was structured in three parts: (1) the biographic life-story section and demographic data; (2) questions about early career experiences (the period within the first five years as a teacher educators at ACEs): considerations underlying their professional choices, motivational factors and dilemmas; and (3) questions about the context, local culture and policy of the institutions in which they were employed, compared to their previous workplace.

\section{Data collection and analysis}

Each interview lasted about 60 minutes and was held in the interviewee's office by appointment. The process was carried out in accordance with the principles of ethics in educational research (AERA, 2004), with full transparency with the research participants regarding the purpose of the interview, maintaining the data and the privacy of the interviewees. At the start, the interviewees were asked to sign a consent form to participate in the study and give their permission to record the conversation. The recorded interviews (audio files) were passed on to a research assistant for transcription. Thus, written transcripts of 10 interviews, of between 6,000 and 9,000 words each, were used for analysis and construction of the findings. 
The data-analysis process was based on the thematic inquiry and categorization approach (Maxwell \& Miller, 2008), which entailed rearrangement of the data, production of major categories, definition of secondary themes based on recurring patterns, and the search for interpretation and meaning of these patterns. In the present case, the thematic analysis of interviews led to outlining two types of choices in the early career of the interviewees (teacher education as a profession and ACE as an academic home), the latter of which contained references to two sub-topics: professional and social.

The reliability of the analysis was examined and verified by two external experts from the same field who were asked to propose a thematic analysis of selected interviews and to indicate prominent categories (Creswell, 2013). This initiated a discussion of the interpretations of the data between the two experts and the author, and when differences of opinion emerged we reached a consensual decision.

\section{Findings}

Life stories presented below indicate the interviewees' choice of teacher education as a profession, which in turn follows the identification of an opportunity to bring significant change to the field of education and to convey their vision in practice. Interviewees also mentioned their sense of belonging to the ACE and the culture of balancing self-worth and product-based worth, as two factors that influence each other, which also constitute significant attraction factors in choosing ACE as an academic home.

At the same time, the interviewees noted the positive climate and emphasized their social relevance as new faculty members, along with their encouragement to create a professional network within and outside the ACE, which was more balanced than in the previous institution in which they worked. Accordingly, the findings section is divided into three themes: (a) balance between educational change in practice and theory (as a factor of choice in teacher education as a profession), (b) balance between self-worth and product-based worth; and (c) balance between social relevance and professional network (both were presented as factors in choosing ACE as an academic home). These balance areas were presented as attraction factors for the interviewees in career choices (Figure 1).

\section{Choosing teacher education as a profession: balancing between educational change in practice and theory}

When the interviewees were asked to explain the motives that led them to choose the profession of educating teachers, they noted that they identified its potential power of to enable an informed approach to balance between theory and practice. The expression of the theory and its applications in the field emerged from the testimony of Prof. A. (male, age -60 , seniority at ACE - 29):

The educational and pedagogical need was always there, so it was very natural to choose colleges, and my focus was not academic or research, but rather pedagogical orientation and education for values. In other words, I felt that the mission was to change a person's actions in practice, and not just write about it. 


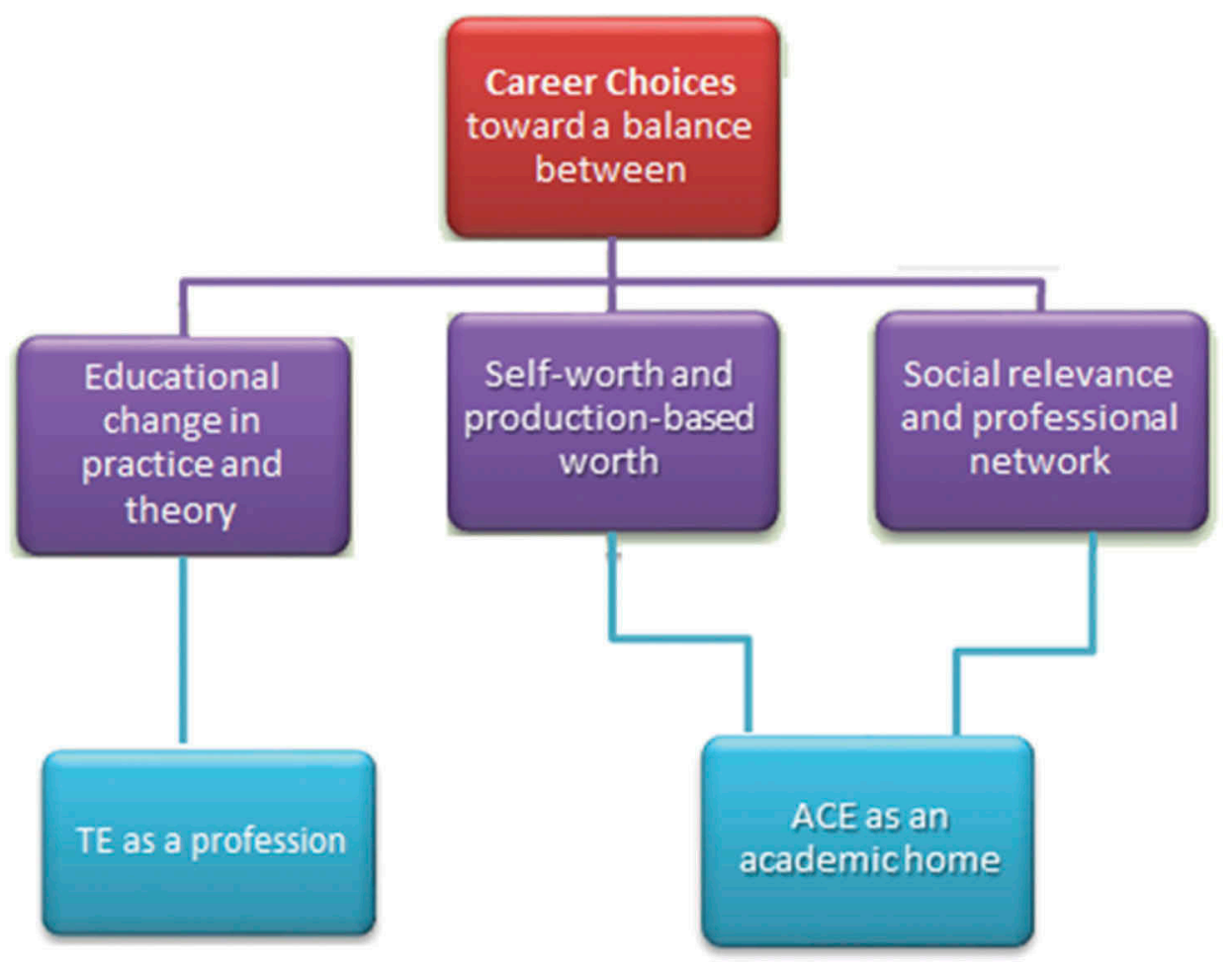

Figure 1. Attracting factors in early career choices among senior teacher educators (illustration of findings).

The other interviewee testified that his choice of teacher educator as a profession derived from the desire to draw full attention to intuition and to connect it closely to the methodology, which is usually guided separately.

Prof. O (male, 65, 21). From an early age I had a connection to pedagogy. It was important for me not only to understand how to do something, but how to teach others to do it, thereby enhancing their personal and professional identity. Today I guide student teachers along this way: they should understand that the balance between intuition and methodology is best implemented in children. And when one knows how to explain this to another child, one learns and is even empowered by it.

Prof. $L$ (female, 59, 22) noted that the approach to the teacher education allowed her to come down from the 'ivory tower', of theory and examine her area of expertise from below, 220 close to the field, noting the practical applications of being taught in academia.

This [profession] allowed me the maximum space for the connection between education and [my field of specialization]. It was not just an academic position where you only worked in the 'ivory tower'. So I saw a lot of opportunities here to develop, and in retrospect they really were. For example, emphasis has been put on developing young leadership through [my area of specialization], and how to transfer it to schools. That is, not only do professionals come to educate the teachers' generation, but they bring a lot of added value. 
These testimonies illustrate the educational-pedagogical potential that existed among the interviewees from an early age. According to them, their choice of profession appeared to be a space in which the appropriate balance between theory and practice can be expressed, thus enhancing their contribution to teacher education.

\section{Choosing ACE as an academic home: balancing between self-worth and production-based worth}

The interviewees talked about the importance of balancing between 'self-worth' with an emphasis on interpersonal skills, and 'production-based worth' in academic terms. This balance proved invaluable, given the emerging insight that university culture does not meet their professional, social, and personal expectations. Prof. D. (female, 55, 20) expressed this precisely:

Originally, this choice was not due to ideological reasons. I wanted to be in university [at school of education] and do research mainly. I met the university standard, which means I was on a tenure track. But I felt very bad there. I was there for three years and for three years I was very lonely. I didn't have anyone to talk to even though they were all nice to me. I felt that all I was expected to do was come into my office, do research, go teach and mentor students and that's it. Later I decided to direct myself to a teacher training college. That was a default for me and I didn't really know what it was. But a short time later, I started to feel at home. I felt significant and important, as I didn't feel there.

Prof. B. and Prof. G. also raised the issue of cultural gaps between institutions, along with the production-based worth as it was at the university, and the balance they found upon the arrival at the ACE.

Prof. B. (female, 66, 32): When I came back I was offered a place at the university in Israel where I had studied until the M.A. degree, but I refused it (although I had a commitment to go back there, as they gave me a small fellowship), because I would not want to live in the atmosphere of 'publish or perish'. And then I started working here, part-time, which expanded quite quickly to full-time. Here, as a lecturer at the college of education, I had a feeling that I had a better chance of growing. They knew how to absorb me, beyond the fact that I had a PhD from the [...] University, which was ranked as a leader in education. There were not many then at all, certainly not in colleges of education.

Prof. G. (female, 59, 24): At the time I was under pressure to stay working at the university and not go to college. But I did not want my career and my salary to be measured by the amount of papers I produced. I felt I could not write under a ticking clock. Not at a level that I have to report every year. I knew that my area of expertise could be applied in colleges of education, and that I could get a good job there. Then I sent my CV to the three colleges and they replied to me within 24 hours.

The issues of the personal professional choice in terms of research activity were repeated in the interviews with Prof. G. and Prof. K:

Prof. G.: A few years later, degrees of academic advancement which depended on the publications were opened, and then I began to persevere in research, but it was motivated by choice, not by pressure. Balancing is a way of life that the college has allowed me during this period. 
Prof. K.: I have to say I was not so academically ambitious, I was pretty humble. I didn't want to be a prisoner in the university race. The only time I deliberately aspired to success was toward the professorship. As soon as this possibility opened, I went into ambition and then put in a deliberate and calculated effort to strengthen academic research and publication, to get it.

These examples illustrate the dilemmas faced by interviewees as university career candidates, and the solution they found by choosing ACE as an academic home, emphasizing the salient advantage the ACE offered - the balance between academic demands, the horizon of a professorship and a sense of well-being and self-worth.

\section{Choosing ACE as an academic home: balancing between social relevance and professional network}

Another significant attraction is reflected in the heartwarming human relationships that the interviewees were able to build in the ACEs, and its balance with the construction of a significant professional network. The interviewees related to the issue of speed of integration into the college from an interpersonal perspective, alongside a promotion horizon that appeared before them.

Prof. Y. (male, 57, 23): I became connected very quickly. After three years I got tenure and started my promotion. It was excellent, and I felt like I was blossoming. I created good interpersonal relationships and then realized how important it was to have friends at work. This is my home; I'm here almost every day. And here I have people that I really love, beyond the fact that we work together.

Prof. A. described the unique spirit of the college, and it was a major attraction for him. Alongside this, professional, social and ideological connections were added, a sense of autonomy that created a balance for the best professional path for him.

The spirit here suited me more than anything else. There is a tradition of progressive education, a humanistic spirit, a socialist approach, which was not present in other institutions in which I worked, where the approach was more technocratic, how to be a technically good teacher. I felt that here I would have more freedom of action and more space to express myself. Then, I quickly became a significant figure at the college. I felt that in particular they [colleagues] were listening to me, taking me in and considering the potential of my contribution, and soon I was called to take up positions on committees. In these ways I began to build a kind of leadership in the college itself.

Finally, Prof. B. mentioned the sense of camaraderie and the interpersonal warmth that characterized the ACE and gave it a relative advantage over the university. This issue was at stake as well as her choice of ACE as an academic home.

Prof. B: They actually gave me an offer to stay (at the university) and I decided not to. I decided I liked it here because there was a sense of home, brotherhood and interpersonal warmth. The person who later became the chairman of the college told me: 'We are a small institution (indeed we were small), but we are growing, and you will grow up with us'. And I took it to my attention. 
The interviewees reflected their personal background that characterized them in an early career. They shared the fact that they had started working at the ACEs as a natural continuation of their doctoral studies at universities, and having taught and practiced in these and other research institutions. The analysis of the interviews clearly indicated a prominent pattern that was repeated in the interviews, manifested in striving for balance in various fields of work. The interviewees noted that upon entering the position at the $A C E$, they found that they could properly combine important issues for their jobs, so that different components of their positions do not come at the expense of others. This was a significant consideration for them in choosing careers, which was not possible, and would not be possible in their work at universities. The fact that the initial steps of academization were synchronized with their entry into the role added an additional weight which allowed for even greater balance between the various components. Hence, the totality of the testimonies presented points to the importance of life-work balance, and the examples reflected three balance points for teacher educators' career choices: (a) self-worth and production-based worth; (b) social relevance and professional network; and (c) educational change in practice and theory.

\section{Discussion}

Research in the field of teacher education in recent years explores in depth the process of shaping professional identity of teacher educators (e.g. Author, 2018; Murray et al., 2011; Shagrir \& Altan, 2014; Wood \& Borg, 2010), which is a cornerstone in the development of their future career. Alongside the widespread discussion of career paths from school teaching to college teaching, there is a conspicuous lack of research examining the emotional, social and cultural processes of teacher educators who came to ACE from an institution with a different academic and research culture, such as university-based schools of education. This study makes an effort to bridge this lacuna, and to examine the attraction factors of early career choices among this group, as well as outline a set of suggestions for ACE principals on issues around hiring and retaining teacher educators with impressive academic achievement. The interpretive analysis sheds light on the interviewees' stories, elucidating the factors influencing their educational growth and their order of priorities in light of the gap between the academic culture from which they had grown and the culture of the academic home in which they had chosen to settle. These changes, which were seen as factors of attraction in career choices, were expressed in three balancing points mentioned above and presented in Figure 1.

This finding can be explained by professional and contextual factors related to interviewees' working lives. At the professional level, it should be taken into account that their integration at the ACEs was a sequential stage after their employment at the universities. The possible interpretation in this regard is that the contrast between two cultures shaped the interviewees' professional identity and led to an assessment of the integration and balance that characterized the ACEs during this period. At the contextual level, the early career of the interviewees was synchronized with the beginning of academization of ACEs, also known under the term 'universitization', namely the attempt of ACEs to model 
themselves for universities in any way possible (Hofman \& Niederland, 2012). This 'new era' brought with it a spirit of assimilation of academic research and teaching culture, alongside the emphasis on the pedagogical aspects in practice, by which the ACEs were characterized since the pre-academic period.

Alongside studies that have discussed professional choices among teachers (Bergmark, Lundström, Manderstedt, \& Palo, 2018; Clandinin et al., 2015) and

Q9 teacher educators (e.g. Author, 2019b; Griffiths et al., 2014; Murray \& Male, 2005), and which have indicated ideological and practical reasons for making a choice in their profession, the present study refines these findings and even adds a new element to them. This small-scale study suggests that beyond the ideological motives of young teacher educators to integrate into ACE, there is a clear presence of individualistic causes such as the need for professional space and social relevance. There are also pragmatic considerations, such as a reluctance to pursue achievements in a university culture, being in a 'publish or perish' culture, excessive research demands, instability, or imbalances in important fields for early career teacher educators.

These findings indicate the adequacy of two concepts: 'career choices' and 'choosing the satisfying lifework', which may serve as a salient conclusion in this study. Despite the known limitations in qualitative research (Maxwell \& Miller, 2008), this conclusion can be used to draw up a set of recommendations for ACE principals on recruiting and retaining academically excellent faculty members. The first recommendation is to place this issue on an agenda as a leading strategy in ACE academic development. It is advisable to downplay concern that this recruitment will damage the social fabric or create a sense of alienation and discomfort among longtime serving teacher educators who do not hold a similar academic orientation, as shown by Ellis et al. (2014). The life-stories of the interviewees in this study illustrate that a teacher education institution may earn human capital that will advance an academic culture without hurting the culture of camaraderie and mutuality typical of many colleges. The second recommendation for ACE principals is to strive for the best balance between theory and practice, in a way that will fill the early career researchers with a sense of mission and doing meaningful work, as revealed in the first part of the findings. Finally, the third recommendation is to design career paths that will include preferred employment terms and shortcuts in obtaining tenure and promotion for excellence in research in general, as well as collaborative faculty research in particular. This pattern may attract 'academic stars' to integrate into the ACE and foster a collaborative culture in the team, as evidenced by the third section of the findings.

The current study helps to elucidate the significant and challenging issues in the professional lives of educators who integrate into an institution with a different academic culture than the one from which they came. Although some studies have explored the ways in which academics cope with challenging new environments in terms of the higher academic standards (Author, 2019b; Margolin, 2011; White, 2014), few sources have chosen to examine the opposite situation in all its complexity and sensitivity. Analysis of this unique group's past experiences may lead to insights into a broader scoping of the dilemmas inherent in the early-career stages of teacher educators as having surfaced in the Israeli context. 


\section{Disclosure statement}

Q10 No potential conflict of interest was reported by the author.

\section{Funding}

Q3 This work was supported by the Mofet Institute.

\section{Notes on contributor}

Dr. Mary Gutman is a researcher and teacher educator at Efrata College of Education. She currently serves as chair of the research authority. She holds a postdoctoral fellowship at the Mofet Institute in Tel Aviv. Her main research interest refers to policy of teaching and teacher education.

\section{ORCID}

Mary Gutman (D) http://orcid.org/0000-0003-1731-9686

\section{References}

AERA. (2004). Ethical standards - III. Guiding standards: Intellectual ownership. Washington: American Educational Research Association.

Ariav, T., Kfir, D., \& Feigin, N., 1. (1993). The "Academization" of teacher education in Israel. Teaching Education, 5(2), 151-161.

Bergmark, U., Lundström, S., Manderstedt, L., \& Palo, A. (2018). Why become a teacher? Student teachers' perceptions of the teaching profession and motives for career choice. European Journal of Teacher Education, 41(3), 266-281.

Clandinin, D. J., Long, J., Schaefer, L., Downey, C. A., Steeves, P., Pinnegar, E., \& Wnuk, S. (2015). Early career teacher attrition: Intentions of teachers beginning. Teaching Education, 26(1), 1-16.

Cochran-Smith, M. (2003). Learning and unlearning: The education of teacher educators. Teaching and Teacher Education, 19(1), 5-28.

Cochran-Smith, M., Stringer Keefe, E., \& Carney, M. C. (2018). Teacher educators as reformers: Competing agendas. European Journal of Teacher Education, 41(5), 572-590.

Council of Higher Education (CHE). (2016). Facts about Israeli higher education 2016. Jerusalem: Author. (In Hebrew.

Q11 Creswell, J. W. (2013). Qualitative inquiry and research design: Choosing among five approaches. Sage.

Douglas, A. S. (2013). Advice from the professors in a university social sciences department on the teaching-research nexus. Teaching in Higher Education, 18(4), 377-388.

Ellis, V., McNicholl, J., Blake, A., \& McNally, J. (2014). Academic work and proletarianisation: A study of higher education-based teacher educators. Teaching and Teacher Education, 40, 33-43.

Ewing, R., \& Manuel, J. (2005). Retaining quality early career teachers in the profession: New teacher narratives. Change: Transformations in Education, 8(1), 1-16.

Fresko, B., \& Nasser-Abu Alhija, F. (2015). Induction seminars as professional learning communities for beginning teachers. Asia-Pacific Journal of Teacher Education, 43(1), 36-48.

Goodwin, A. L., Smith, L., Souto-Manning, M., Cheruvu, R., Tan, M. Y., Reed, R., \& Taveras, L. (2014). What should teacher educators know and be able to do? Perspectives from practicing teacher educators. Journal of Teacher Education, 65(4), 284-302.

Griffiths, V., Thompson, S., \& Hryniewicz, L. (2014). Landmarks in the professional and academic development of mid-career teacher educators. European Journal of Teacher Education, 37(1), 74-90. 
Henry, G. T., Bastian, K. C., \& Fortner, C. K. (2011). Stayers and leavers: Early-career teacher effectiveness and attrition. Educational Researcher, 40(6), 271-280.

Hofman, A., \& Niederland, D. (2012). Is teacher education higher education? The politics of teacher education in Israel, 1970-2010. Higher Education Policy, 25(1), 87-106.

Hulme, M., Beaucham, G., Clark, L., Jephcote, M., Kennedy, A., Magennis, G., \& Cochran-Smith, M. (2015). Analysing teacher education policy: Comparative and historical approaches. Teacher Education in Times of Change, 37.

Katz, E., \& Coleman, M. (2001). The growing importance of research at academic colleges of education in Israel. Education+ Training, 43(2), 82-93.

Kosnik, C., Cleovoulou, Y., Fletcher, T., Harris, T., McGlynn-Stewart, M., \& Beck, C. (2011). Becoming teacher educators: An innovative approach to teacher educator preparation. Journal of Education for Teaching, 37(3), 351-363.

Margolin, I. (2011). Professional development of teacher educators through a" transitional space": A surprising outcome of a teacher education program. Teacher Education Quarterly, 38(3), 7-25.

Q13 Marshall, C., \& Rossman, G. B. (2014). Designing qualitative research. Sage publications.

Maxwell, J. A., \& Miller, B. A. (2008). Categorizing and connecting strategies in qualitative data analysis. Handbook of Emergent Methods, 461-477.

Murray, J., Czerniawski, G., \& Barber, P. (2011). Teacher educators' identities and work in England at the beginning of the second decade of the twenty-first century. Journal of Education for Teaching, 37(3), 261-277.

Murray, J., \& Male, T. (2005). Becoming a teacher educator: Evidence from the field. Teaching and Teacher Education, 21(2), 125-142.

Olsen, B., \& Buchanan, R. (2017). "Everyone wants you to do everything": Investigating the professional identity development of teacher educators. Teacher Education Quarterly, 44(1), 9.

Patton, M. Q. (2002). Qualitative research and evaluation methods (3rd ed.). Thousand Oaks, CA: Sage.

Schuck, S., Aubusson, P., Buchanan, J., Varadharajan, M., \& Burke, P. F. (2017). The experiences of early career teachers: New initiatives and old problems. Professional Development in Education, $1-13$.

Shagrir, L. (2015). Factors affecting the professional characteristics of teacher educators in Israel and in the USA: A comparison of two models. Compare: A Journal of Comparative and International Education, 45(2), 206-225.

Shagrir, L., \& Altan, M. Z. (2014). The expert teacher educator: Characteristics and professional identity. International Journal of University Teaching and Faculty Development, 5(1), 41.

Shamai, S., \& Kfir, D. (2002). Research activity and research culture in academic teachers' colleges in Israel. Teaching in Higher Education, 7(4), 397-410.

Trent, J. (2013). Becoming a teacher educator: The multiple boundary-crossing experiences of beginning teacher educators. Journal of Teacher Education, 64(3), 262-275.

White, E. (2014). Being a teacher and a teacher educator-developing a new identity? Professional Development in Education, 40(3), 436-449.

Williams, J., Ritter, J., \& Bullock, S. M. (2012). Understanding the complexity of becoming a teacher educator: Experience, belonging, and practice within a professional learning community. Studying Teacher Education, 8(3), 245-260.

Wood, D., \& Borg, T. (2010). The rocky road: The journey from classroom teacher to teacher educator. Studying Teacher Education, 6(1), 17-28.

Yemini, M., Holzmann, V., de Wit, H., Sadeh, E., Stavans, A., \& Fadila, D. (2015). The drive to internationalize: Perceptions and motivations of Israeli college directors. Higher Education Policy, 28(3), 259-276. 